\title{
Digestão Total e Parcial de Alguns Componentes de Dietas Contendo Diferentes Níveis de Casca de Soja e Fontes de Nitrogênio, em Bovinos ${ }^{1}$
}

\section{Leandro das Dores Ferreira da Silva ${ }^{2}$, Jane Maria Bertocco Ezequiel ${ }^{3}$, Paulo Sérgio de Azevedo ${ }^{4}$, José Wanderley Cattelan ${ }^{3}$, José Carlos Barbosa ${ }^{3}$, Flávio Dutra de Resende ${ }^{5}$, Flávio Roberto Gonzaga do Carmo ${ }^{6}$}

\begin{abstract}
RESUMO - Este experimento foi realizado para avaliar o efeito de dois níveis de casca de soja (CS) e de três fontes de nitrogênio sobre a digestão total e parcial aparentes no rúmen e nos intestinos. Seis novilhos Holandês x Zebu com idade média de 12 meses e 229 $\mathrm{kg}$ de PV foram fistulados no rúmen e no abomaso e distribuídos em quadrado latino 6x6 e alimentados individualmente ad libitum. $\mathrm{O}$ consumo e as digestibilidades totais e parciais dos nutrientes foram avaliados. Não houve efeito da fonte de proteína sobre o consumo, quantidades de matéria seca (MS), matéria orgânica (MO), proteína bruta (PB), fibra em detergente neutro (FDN) e da fibra em detergente ácido (FDA) no rúmen, no abomaso e nas fezes e sobre os coeficientes de digestibilidades destes componentes. O aumento, porém, do nível de casca de soja elevou os coeficientes de digestibilidade de todos os componentes estudados nos locais do trato digestivo, com exceção nos intestinos, onde o nível de casca de soja não afetou a digestão da PB, FDN e da FDA. Os resultados indicam que a casca de soja pode substituir tanto o milho como, parcialmente, a fração volumosa nas rações de ruminantes. A farinha de subproduto avícola e a amiréia podem substituir o farelo de soja nas rações de bovinos sem reflexos negativos sobre a digestão de seus componentes nutritivos.
\end{abstract}

Palavras-chave: matéria seca, lignina, farinha de subproduto avícola, amiréia, farelo de soja, proteína bruta

\section{Total and Partial Digestion of Some Components of Diets Containing Different Levels of Soybean Hulls and Nitrogen Sources in Steers}

\begin{abstract}
This experiment was conducted to evaluate the effect of two levels of soybean hulls and three sources of protein on the total and partial rumen and intestinal digestion. Six Holstein-Zebu steers averaging twelve months of age and $229 \mathrm{~kg}$ BW were fistulated in the rumen and in the abomasum and distributed in a 6x6 Latin square and fed ad libitum individually. The consumption and the total and partial digestibility of the nutrients were evaluated. There was no effect of the source of protein on consumption, amounts of dry matter (DM), organic matter (OM), crude protein (CP), neutral detergent fiber (NDF) and acid detergent fiber (ADF) in the rumen, abomasum and in the faeces and on the digestibility coefficients of these components. On the other hand, increasing the levels of soybean hulls significantly increased the coefficients of digestibility in the whole digestive tract. However, the levels of soybean hulls did not affect the digestion of CP, NDF and ADF in the intestines. The results indicate that soybean hulls can replace maize, due their degradation similarity, and can partially replace the roughage in rations for ruminants, by having high levels of fiber with great potential and speed of ruminal fermentation. Poultry by-product meal and starea can replace soybean meal without negative effects on the digestion of their nutritive components.
\end{abstract}

Key Words: dry matter, lignin, poultry by-product meal, starea, soybean meal, crude protein

\section{Introdução}

Os resíduos originados na produção agrícola e na agroindústria necessitam de estudos para serem melhor aproveitados na alimentação dos animais domésticos. Esta justificativa se fundamenta na necessidade de se forneceram alimentos alternativos e viáveis economicamente, aos animais, sem concorrer diretamente com a alimentação humana. Vários subprodutos originados de processamentos nas industrias têm potencial de uso, principalmente para os animais ruminantes, e na maioria dos casos com reduções nos custos da produção.

Os ruminantes, para atingirem produções máximas estipuladas pela carga genética, precisam consumir quantidades suficientes de energia, proteína,

\footnotetext{
${ }_{1}^{1}$ Parte da tese de Doutorado em Zootecnia do primeiro autor, apresentada à FCAVJ - UNESP.

2 Professor do Departamento de Zootecnia/CCA. Universidde Estadual de Londrina. Campus Universiário. Rodovia Celo Garcia Cid s/n. Londrina, PR. E.mail: leandro@uel.br ou Idfs52@hotmail.com

3 Professor da FCAVJ - UNESP, Câmpus de Jaboticabal - SP.

4 Mestrando em Zootecnia da FCAVJ - UNESP - Jaboticabal, SP. E.mail: paulotim@ig.com.br

5 Pesquisador do Instituto de Zootecnia de Colina, SP.

${ }^{6}$ Zootecnista, FCAVJ - UNESP - Jaboticabal, SP.
} 
minerais e de algumas vitaminas, não se esquecendo da estrutura física dos alimentos que deve ser considerada quando se deseja otimizar uma ração. Para alcançar níveis produtivos mais elevados, torna-se necessário elevar substancialmente o fornecimento de concentrados, porque os volumosos, geralmente, não apresentam níveis suficientes daqueles nutrientes necessários para maximizar a produção.

A síntese de proteína microbiana no rúmen depende do crescimento e da eficiência dos microrganismos na utilização dos substratos energéticos e nitrogenados. Logo, a fonte de energia é um fator limitante para utilização das frações solúveis das proteínas, por isso, conforme Campos \& Rodrigues (1985), as características de fermentação devem ser favoráveis para o desenvolvimento microbiano. Segundo Miller (1973), deve existir um sincronismo na utilização da proteína e da energia pelos microrganismos para que o uso dos compostos nitrogenados não protéicos tenha resultados positivos no desempenho animal. Por esse motivo, os diferentes alimentos que contêm altos teores de nitrogênio solúvel no rúmen devem ser fornecidos junto com fontes de carboidratos facilmente fermentáveis, para manter a produção de aminoácidos essenciais pelos microrganismos (Campos \& Rodrigues, 1985).

Mansfield \& Stern (1994) afirmaram que a fermentação ruminal pode ser limitada através da disponibilidade de energia ou de proteína e não através da inadequada sincronização na liberação desses nutrientes. No entanto, quando a velocidade de fermentação é intensa pode ocorrer a produção e absorção excessivas de amônia, aumentando com isto a excreção de nitrogênio e o custo de produção (Russell et al.,1992). Por outro lado, o rápido desaparecimento da amônia pode ser atribuído à absorção pela parede ruminal ou à sua utilização pelos microrganismos.

Segundo Campos (1980), além do esterco e da cama têm-se também como resíduos provenientes das atividades avícolas as vísceras não comestíveis, penas, cascas de ovos resultantes das industrializações e resíduos provenientes das incubações. A diversificação de produtos, rapidez no preparo e a ausência de microrganismos nos produtos são fatores que também colaboram para o incremento dessa perspectiva, de onde se deduz haver uma tendência crescente em disponibilidade e maiores qualidades nutritivas dos resíduos (Campos \& Rodrigues, 1985).

Segundo Sperb (1994), o Brasil foi o segundo maior produtor e exportador mundial de carnes de frango, cerca de 3,4 milhões de toneladas de carne e exportou 481 mil toneladas de produtos cárneos avícolas. Dados da ABEF (1995) demonstraram que $50 \%$ dos frangos exportados foram inteiros e o restante em cortes nobres. Enquanto AVES e OVOS (1995) indicaram que o Brasil encerrou 1995 produzindo 4 milhões e 50 mil toneladas de frangos. Estes dados retratam a perspectiva de geração de resíduos na produção e na industrialização dos produtos no setor avícola.

A casca de soja é outro subproduto com grandes perspectivas de uso pela sua disponibilidade e valor nutricional. Segundo Garleb et al. (1988), a casca de soja poderia substituir o uso de forrageiras de alto valor nutricional, quando oferecida aos animais em quantidade controlada. Quicke et al. (1959), ao avaliarem a casca de soja, em ensaios in vitro, encontraram coeficiente de digestibilidade de $96 \%$ para a matéria seca, sugerindo que sua fração fibrosa possui alta digestibilidade, mesmo sendo constituída por $70 \%$ de parede celular.

Vários autores como Sarwar et al. (1991); Bernard \& McNeill (1991), Fischer et al. (1992), Tambara et al. (1992) e Mansfield \& Stern (1994) utilizaram a casca de soja em substituição ao milho em grão, enquanto outros pesquisadores como Felliner \& Belyea (1991) substituíram milho e trigo nas dietas para vacas em lactação por casca do grão de soja e Shain et. al. (1993) a utilizaram exclusivamente com três ingredientes volumosos. Em virtude de apresentar mais de $70 \%$ de parede celular, porém com alta degradabilidade, a casca do grão de soja pode ser considerada um alimento volumoso energético, podendo substituir alimentos concentrados energéticos e/ou parcialmente volumosos.

MacGregor et al. (1976), Anderson et al. (1988), Nakamura \& Owen (1989) e Bernard \& Mcneill (1991) afirmaram que a casca de soja pode substituir alimentos ricos em amido na formulação de concentrados para vacas em lactação, devido ao efeito benéfico sobre a digestibilidade da matéria seca da dieta e na produção de leite. Segundo afirmações de Ludden et al. (1995), a casca de soja apresenta valor estimado de 74 a $80 \%$ do valor nutricional do milho em grão quando incluída de quantidades moderadas a altas em concentrados para bovinos em fase de engorda. Alguns trabalhos demonstraram que a composição química associada à taxa de degradação da casca de soja contribui para que não haja variações bruscas no $\mathrm{pH}$ e na produção de ácidos graxos

R. Bras. Zootec., v.31, n.3, p.1258-1268, 2002 
voláteis ruminais, quando se deseja otimizar o desempenho de animais com alto potencial de produção.

Pelos resultados apresentados na literatura com vacas leiteiras pode-se deduzir que a casca de soja poderá vir a ser uma alternativa suplementar na alimentação de bovinos, mais especificamente, em alimentação de bezerros, visando abates precoces. No entanto, para usá-la deve-se corrigir alguns fatores nutricionais, devido ao fato dela possuir baixos teores de fibra efetiva, havendo necessidade de inclusões de outras fontes fibrosas para obtenção de boas condições no ambiente ruminal, para que ocorra maior eficiência.

Este trabalho foi conduzido com o objetivo de estudar a influência de dois níveis de casca de soja, em substituição ao feno de capim-coastcross e de três fontes de nitrogênio, sobre a digestão total e parcial aparentes no rúmen e no intestino de bovinos, usando-se a lignina como indicador.

\section{Material e Métodos}

O experimento foi conduzido nas dependências do Departamento de Zootecnia da Faculdade de Ciências Agrárias e Veterinárias - FCAV/UNESP, Jaboticabal, SP. Foram usados seis novilhos mestiços (Holandês x Zebu), castrados, com 12 meses de idade, com peso vivo médio de $229,9 \pm 33,2 \mathrm{~kg}$, providos de cânulas no rúmen e no abomaso, distribuídos em modelo de Quadrado latino com seis tratamentos, sendo 2 (dois) níveis de cascas de soja e 3 (três) fontes de nitrogênio.
No início do experimento e a cada 42 dias os novilhos receberam Ivermectina para combater endo e ectoparasitos, sendo submetidos a um período de adaptação às condições de confinamento, em baias individuais com 2,00 $\mathrm{m}$ de comprimento por $1,10 \mathrm{~m}$ de largura, com piso de concreto, portando cochos individuais e bebedouros com níveis de água controlados por bóia. Os animais foram pesados ao término de cada período de 25 dias para ajuste do consumo inicial de matéria seca, quando necessário.

Os alimentos usados nas formulações das rações experimentais foram feno de coast-cross (FCC) e casca do grão de soja (CS), considerados fração volumosa, farelo de soja (FS), amiréia 72\% (AM) e farinha de subprodutos de abatedouro avícola (FSAA), como fontes suplementares de nitrogênio, e grão de milho moído (GMM), para o ajuste energético, e sal mineralizado (SM).

As rações foram isoprotéicas $(13 \% \mathrm{~PB})$, sendo o sal mineralizado misturado na ração concentrada a $0,7 \%$, base na matéria seca (MS). A composição química dos alimentos e das rações está, respectivamente, nas Tabelas 1 e 2 .

O fornecimento de rações aos animais foi ad libitum em duas porções, diariamente, às 8 e às 18 horas, de forma que as sobras nos cochos, em um período de 24 horas, fossem de 5 a $10 \%$ da matéria seca fornecida.

Cada animal, dentro de período, recebeu um dos tratamentos: T1, T3 e T5 composto com 60\% de volumoso com $(70 \%$ de $\mathrm{FCC}+30 \% \mathrm{CS})$ e $40 \%$ de concentrado com milho, SM e uma das fontes de

Tabela 1 - Composição química e bromatológica dos ingredientes usados nas rações estudadas (\%MS $)^{1}$ Table 1 - Chemical composition of the ingredients used in the studied rations (\%DM) ${ }^{1}$

\begin{tabular}{lcccccc}
\hline $\begin{array}{l}\text { Nutrientes } \\
\text { Nutrients }\end{array}$ & $\begin{array}{c}\text { Feno } \\
\text { Hay }\end{array}$ & $\begin{array}{c}\text { Casca de soja } \\
\text { Soybean hulls }\end{array}$ & $\begin{array}{c}\text { Milho moído } \\
\text { Ground corn }\end{array}$ & $\begin{array}{c}\text { Farelo de soja } \\
\text { Soybean meal }\end{array}$ & $\begin{array}{c}\text { Amiréia } \\
\text { Starea }\end{array}$ & $\begin{array}{c}\text { Far. subproduto avícola } \\
\text { Poultryby-product meal }\end{array}$ \\
\hline MS (DM) & 89,99 & 89,99 & 87,70 & 88,19 & 88,73 & 94,17 \\
PB (CP) & 4,82 & 11,95 & 10,01 & 49,87 & 77,01 & 52,15 \\
MO (OM) & 95,50 & 94,75 & 98,54 & 93,02 & 95,99 & 88,87 \\
FDN (NDF) & 89,56 & 77,24 & 9,40 & 26,57 & 27,47 & - \\
FDA $(A D F)$ & 47,23 & 52,64 & 6,72 & 13,02 & 8,16 & - \\
Lignina ${ }^{2}$ Lignin) & 5,16 & 2,21 & & & & - \\
NNP $(P N N)$ & - & - & - & - & 9,79 & 2,02 \\
EE $(E E)$ & 0,86 & 2,40 & 3,24 & 1,72 & 2,69 & - \\
CNF $(F N C)$ & 0,26 & 3,16 & 75,89 & 14,86 & 50,01 & - \\
CT $(T C)$ & 89,82 & 80,40 & 85,29 & 41,43 & 77,48 & \\
\hline
\end{tabular}

1 Obtidos por meio de análise no LANA (Laboratório de Nutrição Animal, FCAV/UNESP, Jaboticabal - SP).

2 Lignina = obtida por meio de oxidação com Permanganato de Potássio.

${ }^{1}$ Data obtained by the analysis at LANA (Animal Nutrition Laboratory, FCAVIUNESP, Jaboticabal - SP).

2 Lignin = obtained by oxidation with potassium permanganate.

\section{R. Bras. Zootec., v.31, n.3, p.1258-1268, 2002}


Tabela 2 - Porcentagem dos ingredientes e composição bromatológica das rações experimentais (\% MS) ${ }^{1}$ Table 2 - Percentage of the ingredients and chemical composition of the experimental rations (\% DM) ${ }^{1}$

\begin{tabular}{|c|c|c|c|c|c|c|}
\hline \multirow[b]{2}{*}{$\begin{array}{l}\text { Ingredientes } \\
\text { Ingredients }\end{array}$} & \multicolumn{6}{|c|}{$\begin{array}{c}\text { Rações experimentais } \\
\text { Experimental rations }\end{array}$} \\
\hline & $\begin{array}{l}70: 30(\mathrm{~T} 1) \\
\text { (FCC:CS) }\end{array}$ & $\begin{array}{l}30: 70(\mathrm{~T} 2) \\
\text { (FCC:CS) }\end{array}$ & $\begin{array}{l}70: 30(\mathrm{~T} 3) \\
\text { (FCC:CS) }\end{array}$ & $\begin{array}{l}30: 70(\mathrm{~T} 4) \\
\text { (FCC:CS) }\end{array}$ & $\begin{array}{l}70: 30(\mathrm{~T} 5) \\
(\mathrm{FCC}: \mathrm{CS}\end{array}$ & $\begin{array}{l}30: 70(\mathrm{~T} 6) \\
\text { (FCC:CS) }\end{array}$ \\
\hline$\overline{\mathrm{FCC}(H C C)}$ & 42,0 & 18,0 & 42,0 & 18,0 & 42,0 & 18,0 \\
\hline $\mathrm{CS}(\mathrm{SH})$ & 18,0 & 42,0 & 18,0 & 42,0 & 18,0 & 42,0 \\
\hline $\operatorname{GMM}(G C G)$ & 26,1 & 30,2 & 27,8 & 31,3 & 31,2 & 33,7 \\
\hline $\mathrm{FS}(S M)$ & 13,2 & 9,1 & - & - & - & - \\
\hline FSAA $(P B M)$ & - & - & 11,5 & 8,0 & - & - \\
\hline $\mathrm{AM}(S T)$ & - & - & - & - & 8,1 & 5,6 \\
\hline \multicolumn{7}{|l|}{ Sal mineral } \\
\hline \multirow[t]{2}{*}{ Mineral salt } & 0,7 & 0,7 & 0,7 & 0,7 & 0,7 & 0,7 \\
\hline & \multicolumn{6}{|c|}{$\begin{array}{c}\text { Composição química e bromatológica } \\
\text { Chemical composition }\end{array}$} \\
\hline $\mathrm{MO}(O M)$ & 95,35 & 95,60 & 92,05 & 91,79 & 95,07 & 95,78 \\
\hline $\mathrm{PB}(C P)$ & 13,60 & 13,70 & 13,20 & 12,90 & 12,90 & 13,90 \\
\hline FDN $(N D F)$ & 61,75 & 59,92 & 61,54 & 60,17 & 61,67 & 57,58 \\
\hline $\operatorname{FDA}(A D F)$ & 31,65 & 33,25 & 31,38 & 32,44 & 31,34 & 32,59 \\
\hline $\mathrm{EE}(E E)$ & 1,20 & 1,61 & 3,17 & 3,52 & 1,99 & 2,37 \\
\hline $\mathrm{CNF}^{2}(F N C)$ & 21,10 & 22,77 & 15,77 & 16,38 & 19,89 & 23,21 \\
\hline $\operatorname{NIDA}^{3}(A D I N)$ & 2,30 & 2,40 & 1,63 & 1,18 & 1,38 & 1,28 \\
\hline Lignina $^{4}$ (Lignin) & 2,95 & 2,25 & 2,80 & 2,11 & 3,00 & 2,25 \\
\hline \multicolumn{7}{|c|}{ 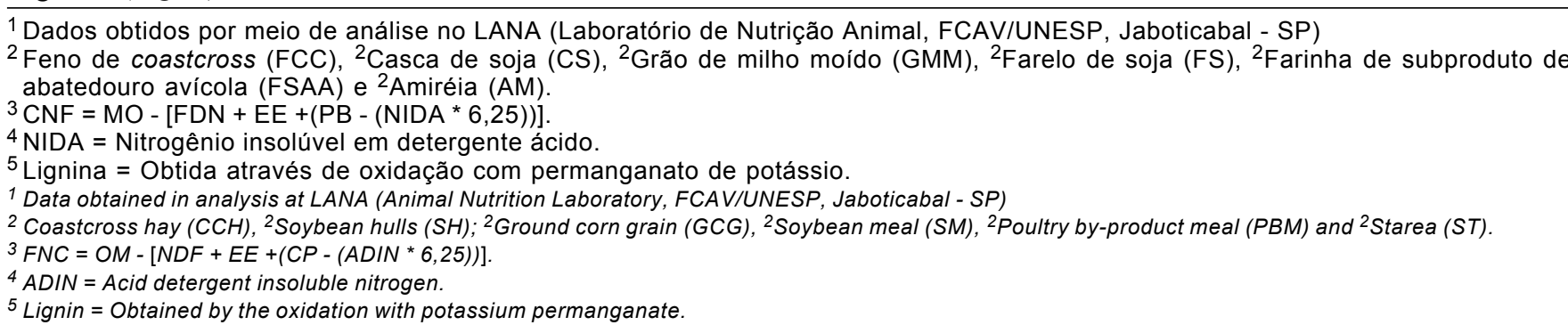 } \\
\hline
\end{tabular}

nitrogênio, respectivamente FS, FSAA e AM e o T2, T4 e T6 composto com $60 \%$ de volumoso com $(30 \%$ de FCC +70 de CS) e $40 \%$ de concentrado descrito anteriormente.

As quantidades de matéria seca (MS), matéria orgânica (MO), proteína bruta (PB), fibra em detergente neutro (FDN), fibra em detergente ácido (FDA), carboidratos não estruturais (CNE), nitrogênio insolúveis em detergente ácido (NIDA) e de lignina presentes no rúmen, foram estimadas a partir da composição da ingestão média de cada um dos componentes nutritivos por animal e período experimental conforme, (Silva \& Leão, 1979). Como indicador interno foram adotados os teores de lignina, sendo usadas as fórmulas citadas por Valadares Filho et al. (1985), para estimar a quantidade de MS nas fezes e a MS da digesta do abomaso em 24 horas.

Após o período de adaptação foram retiradas amostras da digesta do abomaso e das fezes em quatro dias consecutivos, no primeiro dia, às 8,16 , e 00 horas; no segundo dia, às 10,18 , e 2 horas; no terceiro dia, às 12, 20, e 4 horas; e no quarto dia, às 14, 22, e 6 horas. As amostras individuais consistiram de $300 \mathrm{~mL}$ de digesta do abomaso e de $150 \mathrm{~g}$ de fezes que foram acondicionadas em freezer a $-20^{\circ} \mathrm{C}$ até o final do período experimental.

Após o descongelamento, as amostras do abomaso foram homogeneizadas com batedeira manual do tipo Mixer (Hand Blender) e sendo que destas amostras alíquotas de $150 \mathrm{~mL}$, pesando aproximadamente 180 $\mathrm{g}$ foram retiradas, acondicionadas em vasilhames de vidros tipo Pirex e colocadas em estufas a $55^{\circ} \mathrm{C} \pm 5$ ${ }^{\circ} \mathrm{C}$ com circulação forçada de ar por $96 \mathrm{~h}$ para secagem. Em seguida, as amostras foram retiradas dos vasilhames e trituradas em moinho dotado de peneira com crivos de $1 \mathrm{~mm}$ de diâmetro. Foram colhidas $60 \%$ de cada amostra individual, após seca e triturada a $1 \mathrm{~mm}$, misturadas e homogeneizadas, de 
forma que, se obteve uma amostra composta por animal por período.

As amostras das fezes foram descongeladas e homogeneizadas, manualmente, por animal e por período. Alíquotas de $200 \mathrm{~g}$, em vasilhame de alumínio, tipo marmitex, foram colocadas em estufa a $55^{\circ} \mathrm{C}$ $\pm 5^{\circ} \mathrm{C}$ com circulação forçada de ar por $72 \mathrm{~h}$ para secagem. As amostras de fezes foram trituradas em moinho dotado de peneira com crivos de $1 \mathrm{~mm}$ de diâmetro, armazenadas e, posteriormente, analisadas em laboratório.

Nas amostras do feno, da casca de soja, das rações concentradas, das sobras, das digestas do abomaso e das fezes foram determinados os teores de MS, MO, PB, FDN, FDA, NIDA e de lignina, conforme metodologias citadas por Silva (1990).

Os dados obtidos foram submetidos à análise de variância (ANOVA) através do procedimento GLM do SAS, $1990^{\circledR}$ e as diferenças entre médias, detectadas pelo teste de Tukey.

\section{Resultados e Discussão}

A ingestão de matéria seca pelos animais ruminantes é influenciada, em grande parte, pela granulometria e velocidade de digestão dos ingredientes da ração no rúmen, pois, quando alta, ocorre esvaziamento mais rápido deste compartimento, induzindo a maior consumo. Por outro lado, rações trituradas finamente tendem a apresentar maiores taxas de passagens do conteúdo do rúmen-retículo para os compartimentos posteriores do tubo digestivo, acarretando condições para maior consumo de matéria seca da dieta.

Vários autores, na literatura, verificaram que a ingestão de matéria seca de uma ração é inversamente relacionada ao teor de parede celular indigestível que, ocupando espaço no trato gastrointestinal, reduz o consumo. Além da indigestibilidade, as taxas de digestão e de passagem da fibra pelo trato gastrointestinal são altas e positivamente correlacionadas com o consumo (Mertens \& Ely, 1979). No entanto, em muitas outras situações, a ingestão de matéria seca é positivamente correlacionado à digestibilidade da ração (Waldo \& Jorgensen 1981). Outros fatores, como o excesso e/ ou deficiência de fontes nitrogenadas no rúmen podem ter reflexos positivos ou negativos no consumo e na digestibilidade dos componentes da dieta dos animais ruminantes.
Neste trabalho, as fontes protéicas não apresentaram efeitos $(\mathrm{P}>0,05)$, em quaisquer unidades de expressão, sobre a ingestão de matéria seca (MS), proteína bruta $(\mathrm{PB})$ e de fibra em detergente neutro (FDN), Tabela 3.

No entanto, verifica-se que a amiréia (AM) e a farinha de subproduto de abatedouro avícola (FSAA) tenderam a proporcionar maiores consumos de MS, PB e FDN do que o farelo de soja. Estas observações podem ser atribuídas, em parte, à palatabilidade, pois as rações concentradas foram formuladas de forma isoenergéticas, com aproximadamente $75 \%$ de NDT na matéria seca. Por outro lado, as densidades energéticas das rações podem ter sido ligeiramente diferentes, pois, segundo Mertens (1993), quando as rações possuem alta densidade energética há limitação no consumo de matéria seca a níveis do requerimento e, quando baixa, este será limitado pelo efeito de enchimento do alimento. Os consumos de MS e de MO, observados neste estudo, foram semelhantes aos divulgados por Queiroz et al. (1996) com animais Holandês x Zebu alimentados com ração completa na proporção de 50:50\% de volumosos/concentrados.

As quantidades médias ingeridas, presentes no abomaso e eliminadas nas fezes, diariamente, de matéria seca (MS), matéria orgânica (MO), proteína bruta $(\mathrm{PB})$, fibra em detergente neutro (FDN) e de fibra em detergente ácido (FDA) por fontes de proteína, podem ser visualizadas na Tabela 4 .

A ingestão de matéria seca pelos animais ruminantes pode ser influenciada por vários fatores, além da energia, podem ser citados palatabilidade, granulometria e velocidade de digestão dos componentes químicos da ração no rúmen, especialmente da FDN, que tem correlação negativa com a ingestão de matéria seca da dieta. A digestão, sendo mais rápida, induz a maior consumo, ao passo que rações trituradas finamente elevam a taxa de passagem do conteúdo rúmenretículo para os compartimentos posteriores ao rúmen, proporcionando maior consumo da dieta e menores coeficientes de digestão. Neste particular, verificouse que houve apenas tendências em refletir maiores quantidades de digesta no abomaso e de fezes excretadas, quando os animais apresentaram maiores consumo de matéria seca. Estes resultados coincidem com observações relatadas na literatura, em que, à medida que se eleva o consumo de matéria seca, ocorre maior aceleração da taxa de passagem e, conseqüentemente, a quantidade de matéria seca presente nos compartimentos pós-rumen será maior.

R. Bras. Zootec., v.31, n.3, p.1258-1268, 2002 
Tabela 3 - Consumo voluntário de matéria seca (MS), proteína bruta (PB) e de fibra em detergente neutro (FDN), expresso em gramas por dia (g/dia), porcentagem do peso vivo (\%PV) e gramas por unidade do tamanho metabólico $\left(\mathrm{kg}^{0,75}\right)$

Table 3 - Voluntary intake of the dry matter (DM), crude protein (CP) and the neutral detergent fiber (NDF) expressed in (g/day), of the \% BW and $\mathrm{kg}^{0.75}$

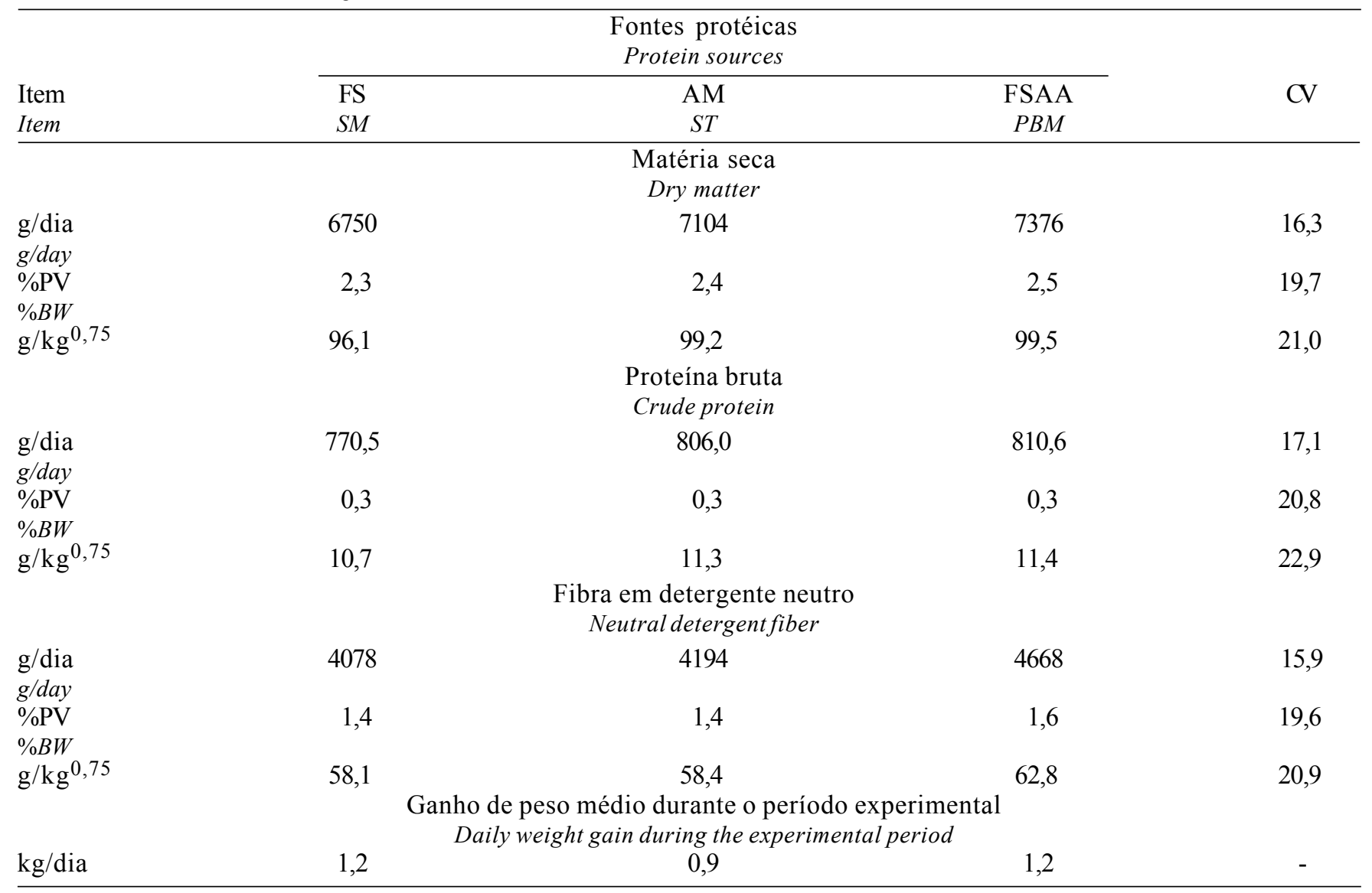

Os coeficientes de digestibilidade aparentes no trato digestivo total, no rúmen e nos intestinos da matéria seca (MS), matéria orgânica $(\mathrm{MO})$, proteína bruta (PB), fibra em detergente neutro (FDN) e da fibra em detergente ácido (FDA), de acordo com a fonte protéica, encontram-se na Tabela 5 .

As digestibilidades da MO das rações não foram afetadas pelas fontes de nitrogênio nos compartimentos digestivos, observando-se a mesma tendência das digestibilidades da MS das dietas. Os desaparecimentos da MO foram semelhantes aos observados por Titgemeyer et al. (1989), Stokes et al. (1991) e Coomer et al. (1993) e próximos aos divulgados por Zinn \& Shen (1998) obtidos com novilhos Holandeses pesando, em média, $249 \mathrm{~kg}$ de $\mathrm{PV}$, alimentados com uréia, farinha de peixes e farelo de soja. Os valores de 72,24 e $69,89 \%$ de digestibilidade da MS e da MO estimados, respectivamente, com amiréia e farelo de soja, neste estudo, foram superiores aos divulgados por
King et al. (1990) e Klusmeyer et al. (1990). Os mesmos autores verificaram que os coeficientes de digestibilidade tenderam a diminuir com a redução de proteína degradável no rúmen.

Em termos de digestão aparente da proteína bruta, no rúmen, espera-se que seja o mais próximo da nulidade possível, quando há sincronismos entre energia e liberação de compostos nitrogenados no rúmen. No entanto, os coeficientes de digestibilidade aparentes da proteína bruta no rúmen, observados no presente trabalho, podem ser devidos, em parte, às altas taxas de degradação da proteína das fontes nitrogenadas divulgadas por Silva et al. (1999), em trabalho conduzido com os mesmos animais e alimentos usados neste estudo, e pela falta de sincronização em tempo e quantidade de cetoácidos em relação à liberação de nitrogênio, necessários para o crescimento bacteriano, sendo, neste caso, difundidos pela parede ruminal. Segundo Silva \& Leão (1979), a 
Tabela 4 - Efeitos das fontes protéicas sobre as quantidades médias diárias de matéria seca (MS), matéria orgânica (MO), proteína bruta (PB), fibra em detergente neutro (FDN), fibra em detergente ácido (FDA) e de carboidratos não fibrosos (CNF) ingeridas, presentes no abomaso e nas fezes

Table 4 - Effects at the protein source on the average daily amounts of dry matter (DM), organic matter (OM), neutral detergent fiber(NDF) and acid detergent fiberADF) intake, present in the abomasum and feces

\begin{tabular}{|c|c|c|c|c|}
\hline \multirow[b]{2}{*}{$\begin{array}{l}\text { Item } \\
\text { Item }\end{array}$} & \multicolumn{3}{|c|}{$\begin{array}{c}\text { Fontes protéicas } \\
\text { Protein sources }\end{array}$} & \multirow[b]{2}{*}{$\mathrm{CV}$} \\
\hline & $\begin{array}{l}\text { FS } \\
S M\end{array}$ & $\begin{array}{c}\mathrm{AM} \\
S T\end{array}$ & $\begin{array}{c}\text { FSAA } \\
P B M\end{array}$ & \\
\hline & & $\begin{array}{l}\mathrm{MS}(\mathrm{g} / \mathrm{dia}) \\
D M(\text { g/day })\end{array}$ & & \\
\hline $\begin{array}{l}\text { Ingerido } \\
\text { Intake }\end{array}$ & 6750 & 7104 & 7376 & 16,3 \\
\hline $\begin{array}{l}\text { Abomaso } \\
\text { Abomasum }\end{array}$ & 3238 & 3460 & 3332 & 24,9 \\
\hline $\begin{array}{l}\text { Fezes } \\
\text { Feces }\end{array}$ & 2098 & 1972 & 2117 & 23,0 \\
\hline & & $\begin{array}{l}\mathrm{MO}(\mathrm{g} / \mathrm{dia}) \\
O M(\mathrm{~g} / \mathrm{dav})\end{array}$ & & \\
\hline $\begin{array}{l}\text { Ingerido } \\
\text { Intake }\end{array}$ & 6446 & 6815 & 7019 & 16,4 \\
\hline $\begin{array}{l}\text { Abomaso } \\
\text { Abomasum }\end{array}$ & 2531 & 2735 & 2637 & 26,1 \\
\hline $\begin{array}{l}\text { Fezes } \\
\text { Feces }\end{array}$ & 1935 & 1798 & 1928 & 23,6 \\
\hline & & $\begin{array}{l}\mathrm{PB}(\mathrm{g} / \mathrm{dia}) \\
C P(\text { g/day })\end{array}$ & & \\
\hline $\begin{array}{l}\text { Ingerido } \\
\text { Intake }\end{array}$ & 753 & 806 & 846 & 17,6 \\
\hline $\begin{array}{l}\text { Abomaso } \\
\text { Abomasum }\end{array}$ & 587 & 621 & 667 & 18,2 \\
\hline $\begin{array}{l}\text { Fezes } \\
\text { Feces }\end{array}$ & 317 & 285 & 324 & 21,9 \\
\hline & & $\begin{array}{l}\mathrm{FDN}(\mathrm{g} / \mathrm{dia}) \\
N D F(\text { g/day })\end{array}$ & & \\
\hline $\begin{array}{l}\text { Ingerido } \\
\text { Intake }\end{array}$ & 4078 & 4194 & 4668 & 15,9 \\
\hline $\begin{array}{l}\text { Abomaso } \\
\text { Abomasum }\end{array}$ & 1442 & 1513 & 1412 & 25,4 \\
\hline Fezes & 1342 & 1284 & 1310 & 24,4 \\
\hline Feces & & $\begin{array}{l}\mathrm{FDA}(\mathrm{g} / \mathrm{dia}) \\
A D F(\mathrm{~g} / \text { day })\end{array}$ & & \\
\hline $\begin{array}{l}\text { Ingerido } \\
\text { Intake }\end{array}$ & 2152 & 2235 & 2311 & 17,4 \\
\hline $\begin{array}{l}\text { Abomaso } \\
\text { Abomasum }\end{array}$ & 1212 & 1316 & 1237 & 24,6 \\
\hline $\begin{array}{l}\text { Fezes } \\
\text { Feces }\end{array}$ & 1244 & 1156 & 1133 & 25,6 \\
\hline
\end{tabular}

${ }^{1}$ Farelo de soja (FS), Amiréia (AM), Farinha de subproduto de abatedouro avícola (FSAA).

${ }^{1}$ Soybean meal (SM), Starea (ST), Poultry by-product meal (PBPM).

quantidade de nitrogênio encontrado nos compartimentos posteriores ao rúmen pode ser influenciada pelos teores de nitrogênio da ração, fontes de nitrogênio ou por compostos nitrogenados de origens não dietéticas. Em parte, estas observações podem justificar os coeficientes de digestibilidade da PB obtidos no rúmen ou pela maior síntese de proteína microbiana, já que foi observada alta digestão da matéria orgânica neste compartimento digestivo.

As fontes de nitrogênio não afetaram a digestão da FDN e da FDA no trato digestivo total, no rúmen e nos intestinos. No entanto, como preconizado na 
Tabela 5 - Efeitos das fontes protéicas sobre o coeficiente total aparente de digestão ruminal e intestinal da matéria seca (MS), matéria orgânica (MO), proteína bruta (PB), fibra em detergente neutro (FDN) e da fibra em detergente ácido (FDA)

Table 5 - Effects of the protein source ${ }^{1}$ on the total apparent digestibility coefficient ruminal and intestinal of dry matter(DM), organic matter(OM), crude protein(CP), neutral detergent fiber(NDF) and acid detergent fiber(ADF)

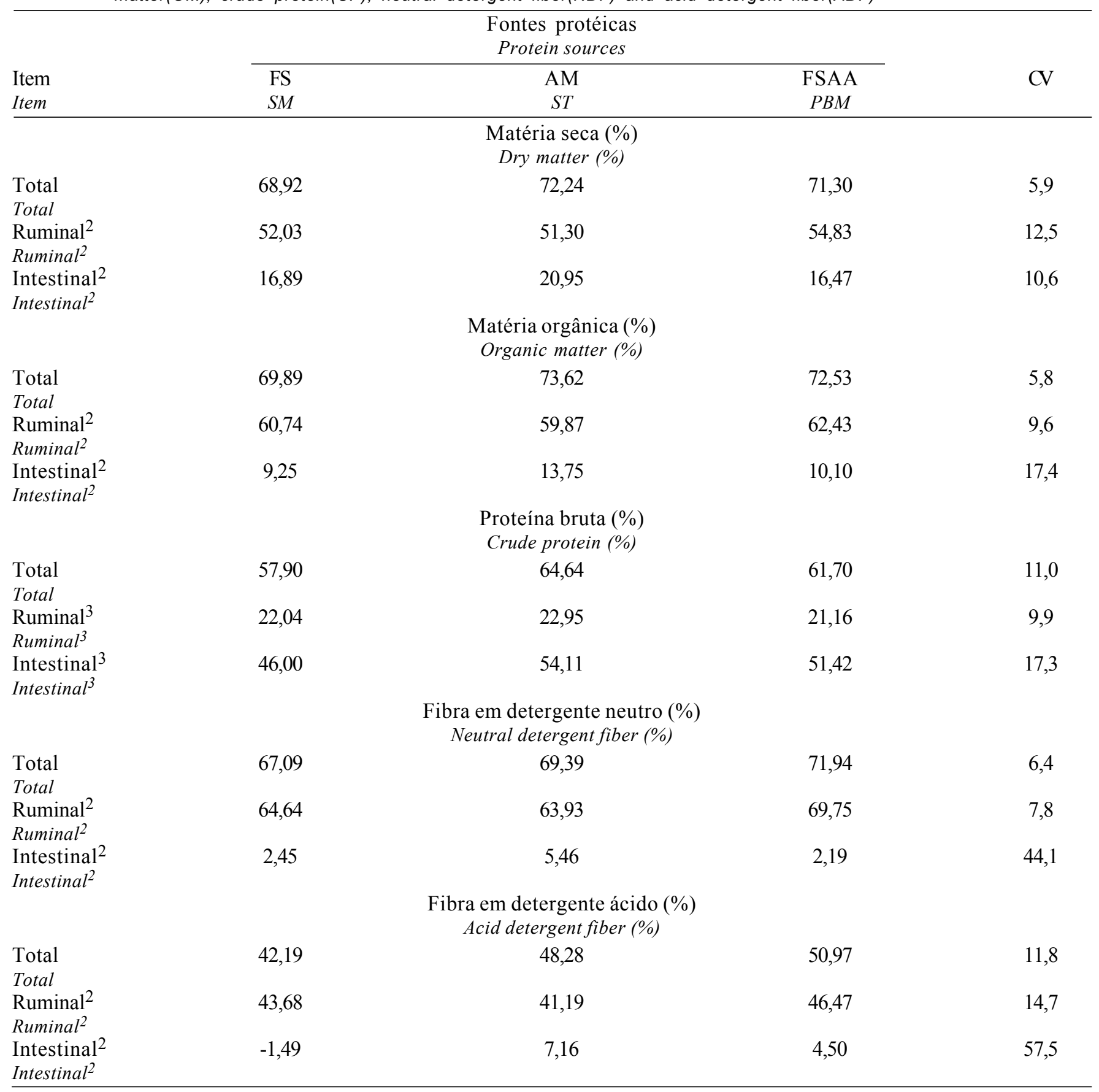

\footnotetext{
${ }^{1}$ Farelo de soja (FS), Amiréia (AM), Farinha de subproduto de abatedouro avícola (FSAA).

1 Soybean meal (SM), Starea (ST), Poultry by-product meal (PBPM).

$2 \%$ do total digestível.

$3 \%$ da quantidade que chegou em cada local $(P>0,05)$.
}

literatura, as taxas de digestão da fração fibrosa das rações nos intestinos foram baixas. Pelos resultados obtidos neste estudo, pode-se afirmar que tanto a FDN como a FDA apresentaram potencial de uso como indicadores internos para estimar o fluxo da digesta nos intestinos de bovinos.

A semelhança na digestibilidade da FDN e da FDA no rúmen entre as fontes de nitrogênio pode ser

R. Bras. Zootec., v.31, n.3, p.1258-1268, 2002 
devida à quantidade semelhante de nitrogênio amoniacal disponível no rúmen para os microrganismos. Entretanto, Firkins et al. (1986) relataram que a concentração de nitrogênio amoniacal não foi correlacionada com a digestão da FDN e FDA. Sabe-se que, quando a concentração de nitrogênio amoniacal for menor que $5 \mathrm{mg} / \mathrm{dL}$, ocorre redução na extensão da digestão em dietas com teores de fibra moderadamente altos.

Nesse sentido, Azevedo (1998) encontrou valores de 22,49; 16,50 e 14,95 mg/dL de nitrogênio amoniacal, respectivamente, para fontes amiréia, farelo de soja e farinha de subproduto de abatedouro avícola, níveis considerados satisfatórios para o crescimento dos microrganismos no rúmen. Neste caso, esperava-se que houvesse maior digestão da FDN das rações com amiréia, devido à maior biodisponibilidade de nitrogênio no rúmen. Clarck \& Davis (1983), porém, relataram que a concentração de nitrogênio amoniacal no rúmen para maximizar o crescimento microbiano é constante para todas as condições de dietas. Por outro lado, Faulkner et al. (1994) afirmaram que o aumento na digestibilidade da FDN e da FDA das rações foi devido à maior quantidade de fibra potencialmente degradável da casca de soja comparada com a do milho moído.

O nível de casca de soja não teve efeito sobre as quantidades de MS, MO, PB, FDN e de FDA no rúmen e nos intestinos (Tabela 6). No entanto, 70\% de casca de soja nas rações proporcionaram maiores $(\mathrm{P}<0,05)$ quantidades de $\mathrm{PB}$ no abomaso do que aquelas com $30 \%$.

$\mathrm{O}$ aumento de casca de soja nas rações elevou significativamente $(\mathrm{P}<0,05)$ a digestibilidade da matéria seca, matéria orgânica e dos carboidratos não fibrosos no trato digestivo total e nos intestinos, (Tabela 7).

Os coeficientes de digestibilidades da MS e da MO encontrados, neste estudo, foram semelhantes aos divulgados por Ludden et al. (1995). No entanto, estes autores verificaram que as digestibilidades da MS e a da MO foram reduzidas com o aumento do nível de substituição do milho por casca de soja.

Segundo Bernard \& McNeill (1991), o uso da casca de soja não deveria exceder a $28 \%$ da MS da dieta como fonte de fibra de rações com alto teor energético. Enquanto Sarwar et al. (1991) afirmaram que níveis elevados de casca de soja nas rações podem reduzir a digestibilidade dos componentes nutritivos da ração, Nakamura \& Owen (1989) relataram que o decréscimo na digestibilidade dos componentes nutritivos das rações foi devido ao aumento da taxa de passagem. Contudo, os resultados obtidos no presente estudo permitem sugerir que a casca de soja pode substituir parte do feno nas rações dos bovinos, sem prejuízos nas taxas de digestão destes componentes químicos.

Tabela 6 - Efeitos dos níveis de casca de soja sobre as quantidades médias diárias de matéria seca (MS), matéria orgânica (MO), proteína bruta (PB), fibra em detergente neutro (FDN) e fibra em detergente ácido (FDA) ingeridas e presentes no abomaso e nas fezes

Table 6 - Effect of the soybean hull level on the average daily amounts of dry matter(DM), organic matter(OM), crude protein(CP), neutral detergent fiber(NDF) and acid detergent fiber(ADF) intake, abomasum present and faeces

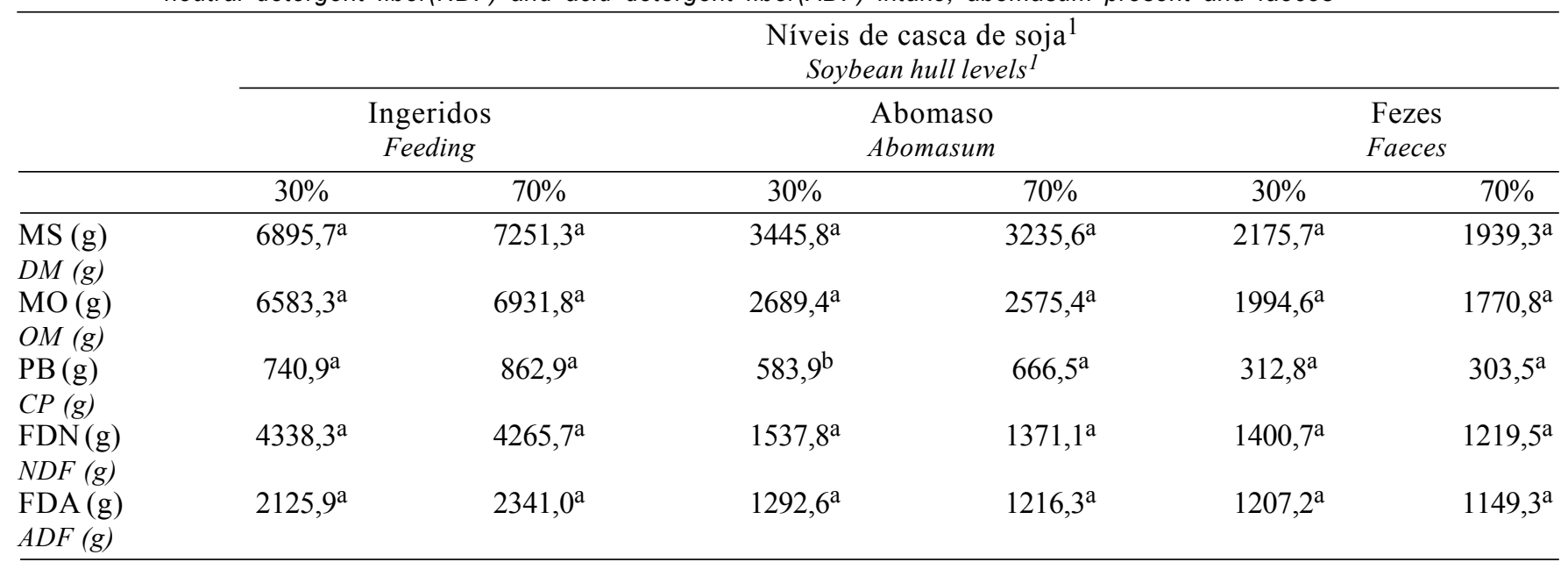

Médias seguidas de letras iguais na mesma linha para o mesmo compartimento não diferem estatisticamente pelo teste Tukey $(P>0,05)$ Means in the same row, for the same compartment, followed by same letters, did not differ by Tukey test $(P>.05)$.

${ }^{1}$ Níveis de casca de soja em substituiçôes ao feno de coastcross (Soybean hull levels replacing the coastcross hay).

R. Bras. Zootec., v.31, n.3, p.1258-1268, 2002 
Tabela 7 - Efeitos dos níveis de casca de soja sobre os coeficientes de digestão aparente total, ruminal e intestinal da matéria seca (MS), matéria orgânica (MO), proteína bruta (PB), fibra em detergente neutro (FDN), fibra em detergente ácido (FDA) e de carboidratos não-fibrosos (CNF)

Table 7 - Effects of the soybean hull level on the total, ruminal and intestinal apparent digestibility coefficient of dry matter (DM), organic matter (OM), crude protein (CP), neutral detergent fiber (NDF), acid detergent fiber (ADF) and non fiber carboydrates (NSF)

\begin{tabular}{|c|c|c|c|c|c|c|}
\hline \multirow[t]{3}{*}{$\begin{array}{l}\text { Nível }^{1} \\
\text { Level }^{1}\end{array}$} & \multicolumn{6}{|c|}{$\begin{array}{l}\text { Digestibilidade aparente no trato digestivo total }(\%) \\
\text { Apparent digestibility in the total digestive tract }\end{array}$} \\
\hline & MS & $\mathrm{MO}$ & PB & FDN & FDA & $\mathrm{CNF}$ \\
\hline & $D M$ & $O M$ & $C P$ & $N D F$ & $A D F$ & $N S F$ \\
\hline $30 \%$ & $68,45^{\mathrm{b}}$ & $69,70^{b}$ & $57,78^{b}$ & $67,71^{b}$ & $43,22^{b}$ & $71,7^{b}$ \\
\hline \multirow[t]{2}{*}{$70 \%$} & $73,26^{\mathrm{a}}$ & $74,45^{\mathrm{a}}$ & $64,83^{\mathrm{a}}$ & $71,41^{\mathrm{a}}$ & $50,91^{\mathrm{a}}$ & $79,8^{a}$ \\
\hline & \multicolumn{6}{|c|}{$\begin{array}{l}\text { Digestibilidade aparente no rúmen } \\
\text { Rumen apparent digestibility }\end{array}$} \\
\hline $30 \%$ & $50,03^{b}$ & $59,15^{\mathrm{a}}$ & $21,19^{\mathrm{a}}$ & $64,55^{\mathrm{a}}$ & $39,20^{\mathrm{b}}$ & $40,2^{b}$ \\
\hline \multirow[t]{2}{*}{$70 \%$} & $55,38^{\mathrm{a}}$ & $62,85^{\mathrm{a}}$ & $22,76^{\mathrm{a}}$ & $67,86^{\mathrm{a}}$ & $48,04^{\mathrm{a}}$ & $47,9^{\mathrm{a}}$ \\
\hline & \multicolumn{6}{|c|}{$\begin{array}{l}\text { Digestibilidade nos intestinos } \\
\text { Intestines digestibility }\end{array}$} \\
\hline $30 \%$ & $18,42^{\mathrm{b}}$ & $10,55^{\mathrm{b}}$ & $36,59^{\mathrm{a}}$ & $3,16^{\mathrm{a}}$ & $4,02^{\mathrm{a}}$ & $52,6^{\mathrm{b}}$ \\
\hline $70 \%$ & $17,88^{\mathrm{a}}$ & $11,61^{\mathrm{a}}$ & $42,07^{\mathrm{a}}$ & $3,55^{\mathrm{a}}$ & $2,86^{\mathrm{a}}$ & $60,2^{\mathrm{a}}$ \\
\hline
\end{tabular}

Médias na mesma coluna para o mesmo local de digestão entre níveis seguidas de letras iguais não diferem $(P>0,05)$. pelo teste Tukey. Means within the same column, in the same digestion site, followed by same letters did not differ by Tukey test $(P>05)$.

${ }^{1}$ Níveis de casca de soja em substituição ao feno de coastcross (Soybean hull levels replacing the coastcross hay).

\section{Conclusões}

A casca de soja tem digestão e qualidades superiores ao feno de capim-coastcross, podendo substituí-lo, parcialmente, na fração volumosa da dieta dos ruminantes.

A amiréia e a farinha de subprodutos de abatedouro avícola podem substituir total ou parcialmente o farelo de soja nas rações de bovinos de corte, sem prejuízos sobre o consumo e a digestão da matéria seca, matéria orgânica, proteína bruta e da fração fibrosa das rações estudadas.

\section{Literatura Citada}

ASSOCIAÇÃO BRASILEIRA DOS PRODUTORES E EXPORTADORES DE FRANGO - ABPEF. Poultry for export, v.2, n.22, p.2-34, 1995.

ANDERSON, S.J.; MERRILL, J.K.; KLOPFENSTEIN, T.J. Soybean hulls as an energy supplement for the grazing ruminant. Journal of Animal Science, v.66, n.11, p.29592964, 1988.

ASSOCIAÇÃO PAULISTA DE AVICULTURA - APA. Tabelas de avicultura. Aves e Ovos, v.12, n.2, 1995.

AZEVEDO, P.S. A casca do grão de soja em substituição ao feno de gramínea nas rações com diferentes fontes protéicas para bovinos. Jaboticabal: Universidade Estadual Paulista, 1998. 53p. Dissertação (Mestrado em Zootecnia) Universidade Estadual Paulista, 1998.

BERNARD, J.K.; McNEILL, W.W. Effect of high fiber energy supplements on nutrient digestibility and milk production of lactating dairy cows. Journal of Dairy Science, v.74, p.991-995, 1991.

CAMPOS, E.J. Aproveitamento de subprodutos da incubação. In: Tópicos avícolas. 1980. p.379-386.

CAMPOS, O.F.; RODRIGUES, A.A. Uréia para bovinos em crescimento. Coronel Pacheco: EMBRAPA/CNPGL, 1985. 42p.

CLARCK, J.H.; DAVIS, C.L. Future improvement of milk production: potential for nutritional improvement. Journal of Animal Science, v.57, n.2, p.750-764, 1983.

COOMER, J.C.; AMOS, H.E.; FROETSCHEL, M.A. et al. Effects of supplemental protein source on ruminal fermentation, protein degradation, and amino acid absorption in steers and on growth and feed efficiency in steers and heifers. Journal of Animal Science, v.71, n.10, p.30783086, 1993.

CUNNINGHAM, K.D.; CECAVA, M.J.; JOHNSON, T.R. Nutrient digestion, nitrogen, and amino acid flows in lactating cows fed soybean hulls in place of forage or concentrate. Journal of Dairy Science, v.76, p.3523-3535, 1993.

FAULKNER, D.B.; HUMMEL, D.F.; BUSKIRK, D.D. et al. Performance and nutrient metabolism by nursing calves supplemented with limited or unlimited corn or soyhulls. Journal of Animal Science, v.72, p.470-477, 1994.

FELLINER, V.; BELYEA, R.L. Maximizing gluten feed in corn silage diets for cows. Journal of Dairy Science, v.74, p.996-1005, 1991.

FIRKINS, J.L.; BERGER, L.L.; MERCHEN, N.R. et al. Effects of forage particle size, level of feed intake and supplemental protein degradability on microbial protein synthesis and site of nutrient digestion in steers. Journal of Animal Science, v.62, n.4, p.1081-1094, 1986.

FISCHER, V.; MÜHLBACH, P.R.F.; ALMEIDA, J.E.L. et al. Efeito da substituição do grão de milho por casca de soja no 
desempenho de bovinos confinados. In: REUNIÃO ANUAL DA SOCIEDADE BRASILEIRA DE ZOOTECNIA, 29., 1992, Lavras. Anais... Lavras: 1992. p26.

GARLEB, K.A.; FAHNEY Jr., G.C.; LEWIS, S.M. et al. Chemical composition and digestibility of fiber fractions of certain byproduct feedstuffs fed to ruminant. Journal of Animal Science, n.66, p.2650-2660, 1988.

KING, K.J.; HUBER, J.T.; SADIK, M., et al. Influence of dietary protein sources on the amino acid profiles available for digestion and metabolism in lactating cows. Journal of Dairy Science, n.73, p.3208-3213, 1990.

KLUSMEYER, T.H.; McCARTHY, Jr., R.D.; CLARK, J.H. et al. Effects of source and amount of protein on ruminal fermentation and passage of nutrients to the small intestine of lactating cows. Journal of Dairy Science, n.73, p.35263532, 1990.

LUDDEN, P.A.; CECAVA, M.J.; HENDRIX, K.S. The value of soybean hulls as a replacement for corn in beef cattle diets formulated with or without added fat. Journal of Animal Science, n.73, p.2706-2711, 1995.

MAcGREGOR, C.A.; OWEN, F.G.; McGILL, L.D. Effect of increasing ration fiber with soybean mill run on digestibility and lactation performance. Journal of Dairy Science, n.59, p.682-672, 1976.

MANSFIELD, H.R.; STERN, M.D. Effects of soybean hulls and lignosulfonate-treated soybean meal on ruminal fermentation in lactating dairy cows. Journal of Dairy Science, v.77, n.4, p.1070-1083, 1994.

MERTENS, D.R. Rate and extent of digestion. In: FORBES, J.M.; FRANCE, J. (Eds.) Quantitative aspects of ruminant digestion and metabolism. Wallingford: $\mathrm{CAB}$ International, 1993. p.13-51.

MERTENS, D.R.; ELY, L.O. A dynamic model of fiber digestion and passage in the ruminant for evaluating forage quality. Journal of Animal Science, v.49, n.4, p.1085-1095, 1979.

MILLER, E.L. Symposium on nitrogen utilization by the ruminant. Evaluation of foods as sources of nitrogen and amino acids. The Proceedings of the Nutrition Society, n.79, p.1-32, 1973.

NAKAMURA, T.; OWEN, F.G. High amounts of soyhulls for pelleted concentrate diets. Journal of Dairy Science, n.72, p.988-994, 1989.

QUEIROZ, A.C.; SANCHEZ, N.R.; RESENDE, F.D. et al. Tamanho médio de partícula, módulo de finura e de uniformidade da digesta ao longo do trato gastrintestinal de ruminantes de diferentes grupos genéticos. Revista Brasileira de Zootecnia, v,25, n.1, p.125-141, 1996.

QUICKE, G.V.; BENTLEY, C.G.; SCOTT, H.W. et al. Digestibility of soybean hulls and flakes and the in vitro digestibility of the cellulose in various milling by-products. Journal of Dairy Science, v.42, p.185-190, 1959.

RUSSEL, J.B.; O'CONNOR, J.D.; FOX, D.G. et at. A net carbohydrate and protein systein for evaluating cattle diets: I. ruminal fermentation. Journal of Dairy Science, v.70, n.11, p.3551-3561, 1992.

SARWAR, M.; FIRKINS, J.L.; EASTRIDGE, M.L. Effect of neutral detergent fiber of forage with soyhulls and corn gluten feed for dairy heifers. Journal of Dairy Science, v.74, p.1006-1017, 1991.
SAS INSTITUTE. User's guide: statistics. 4.ed. Cary: 1990. 956p.

SHAIN, D.H.; SINDT, M.H.; GRANT, R.J. et al. Effect of soybean hull:soy lecithin:soapstock mixture on ruminal digestion and performance of growing beef calves and lactating dairy cattle. Journal of Dairy Science, v.71, n.4, p.12661275, 1993.

SILVA, D.J. Análise de alimentos (Métodos químicos e biológicos). 2.ed. Viçosa, MG: Universidade Federal de Viçosa, 1990. 165 p.

SILVA, J.F.C.; LEÃO, M.I. Fundamentos de nutrição de ruminantes. Piracicaba: Livroceres, 1979. 380p.

SILVA, L.D.F.; EZEQUIEL, J.M.B.; AZEVEDO, P.S. et al. Degradabilidade ruminal in situ da matéria seca, matéria orgânica e da proteína bruta de alguns alimentos em novilhos. Revista Cultural e Científica da Universidade Estadual de Londrina, Semina, Ciência Agrícola, v.20, n.1, p.25-30, 1999.

SPERB, V. Balanço das exportações 1994. Poultry for Export, n.22, p.2-34, 1995.

STOKES, S.R.; HOOVER, W.H.; MILLER, T.K. et al. Ruminal digestion and microbial utilization of diets varyin in type of carbohydrate and protein. Journal of Dairy Science, n.74, p.871-881, 1991.

TAMBARA, A.A.C.; OLIVO, C.J.; SILVA, J.H.S. et al. Substituição do milho por casca moída em rações para vacas holandesas em lactação, durante o verão. 2 Composição físico químico do leite. In: REUNIÃO ANUAL DA SOCIEDADE BRASILEIRA DE ZOOTECNIA, 29., 1992, Lavras. Anais... Lavras: Sociedade Brasileira de Zootecnia, 1992, p.146.

TITGEMEYER, E.C.; MERCHEN, N.R.; BERGER, L.L. Evaluation of soybean meal, corn gluten meal, blood meal and fish meal as sources of nitrogen and amino acids disappearing from the small intestine of steers. Journal of Animal Science, v.67, n.1, p.262-275, 1989.

VALADARES FILHO, S.C.; SILVA, J.F.C.; LEÃO, M.I. et al. Óxido crômico e lignina na determinação dos fluxos de matéria seca abomasal, ileal e fecal em bovinos e bubalinos. Revista Brasileira de Zootecnia, v.14, n.5, p.565-574, 1985.

WALDO, D.R.; JORGENSEN, N.S. Forage for high aniaml production: nutritional factors and effects of conservation. Journal of Dairy Science, v.64, p.1207-1229, 1981.

ZINN, R.A.; SHEN, Y. An evaluation of ruminally degradable intake protein and metabolizable amino acid requeriments of feedlot calves. Journal of Animal Science, v.76, p.1280-1289, 1998.

Recebido em: 11/04/01

Aceito em: 21/01/02 